\title{
Fuzzy Approach for Heat Exchanger Network
}

\author{
Dina S. \\ Chemical \& Petroleum Process \\ Engineer at Nasr Petroleum \\ Company
}

\author{
M.H. Hussein \\ Assistant Professor in \\ Chemical Engineering \\ Department \\ High Institute of Engineering \\ Shorouk Academy
}

\author{
M.E. Awad \\ Associate Professor \\ Chemical and Petroleum \\ Refining Engineering \\ Department \\ Suez University
}

\begin{abstract}
A systematic method for synthesis of heat exchanger networks by using fuzzy approach is presented in this paper, the proposed method consists of three sequential steps to select the optimal approach temperature: i) estimation of minimum approach temperature, minimum hot utility and minimum cold utility. ii) Fuzzy approach. iii) Selection of the best weight index. The proposed method has been applied for two problems well-known in published literature. The results of these case studies show that the present strategy is simple and accurate in finding out global optimum in comparison with previous works, characterized by its simplicity and can be implemented by hand calculations.
\end{abstract}

\section{Keywords}

Process Synthesis, Fuzzy Approach, Energy saving, Heat Recovery, Heat Integration, Heat Exchanger Network.

\section{INTRODUCTION}

Chemical plants need efficient management of energy. For this purpose, an optimum integration of supply and removal of heat among the process streams is required. The most important equipment in energy integration is heat exchanger. A heat exchanger exchanges heat between a hot and a cold process stream: the hot stream cools down to the desired temperature and the cold stream becomes hot to the desired level. Based on the heat load, the heat exchange area is determined. The exchanger is fabricated based on this area. A network of heat exchangers is usually used in a process plant.

Design of the best heat exchanger network is an optimization problem where the total cost is to be minimized. The total cost comprises of the cost of the exchanger units and the cost of the utilities. Cost of the exchanger is directly related to the heat exchange area. The cost of hot and cold utilities is based on their unit cost and annual consumption. Masso and Rudd [1] first defined the network design problem in a rigorous manner. They proposed minimization of the total cost for designing an optimum heat exchanger network. Since then, more than 500 publications have appeared in the literature in search of the method, which can find the least-cost network. A recent article by Furman and Sahinidis [2] provides an excellent review on the subject.

In heat exchanger network design several heuristics are used. Some examples of these heuristics are minimization of number of exchangers, splitting of process streams, minimization of the consumption of utility and use of the cheapest utility. Although suitable for a particular problem, these heuristics do not provide any general guideline, which can ensure that following a particular set of them will ensure the best network. Although there have been many publications on the design of heat exchanger networks during the past three decades, the problem is still open for further research. Mainly two approaches are noted in these works: (a) pinch method and (b) optimization techniques. in process design The pinch method has been a landmark development Linnhoff \& Hindmarsh, [3]. This method is based on the first and second laws of thermodynamics. The main objective of this method is to save expenses by maximizing process-to-process heat recovery. This also reduces the external utility (e.g., steam and cooling water) load.

Successful work has been done on heat exchanger network synthesis (HEN) using both pinch technology and MINLP techniques. Such developments have been reviewed in a number of publications Linnhoff \& Flower, [4, 5]; Linnhoff \& Ahmad, [6] Papoulias \& Grossmann, [7, 8]; Yee \& Grossmann, $[9,10]$.

According to Ravagnani et al. [11], several kinds of studies were done aiming to develop methodologies to obtain optimal HEN to reach these goals. Research was concentrated in three important areas, Pinch Analysis, which uses thermodynamic concepts, Heuristics and Mathematical Programming, such as (LP), (NLP), (MILP), and (MINLP). Recently, heuristic methods of optimization have also been used to solve linear and non-linear models Hussein [12]

Recent approaches with both techniques have shown to be capable of synthesizing near optimal networks for real industrial problems. However, not much has been done to ensure that the resulting networks are fully consistent with what is finally achieved in terms of industrial hardware. Although most of the current synthesis techniques are based on the assumption of constant film heat transfer coefficients

In this paper a new systematic method for synthesis of heat exchanger networks has been presented, the proposed method consists of three sequential steps to select the optimal approach temperature, the results of case studies show that Fuzzy approach is simple in finding out global optimum minimum approach temperature in comparison with previous works.

\section{PROBLEM STATEMENT}

The Heat exchanger network synthesis problem to be addressed in this paper can be stated as follows: A set of hot streams to be cooled and cold streams to be heated are given which include stream data with inlet and outlet stream temperatures, heat capacity flow rates and heat transfer coefficients. In addition, a set of hot and cold utilities are specified. The basic objective of the HENS problem is to synthesize a network of heat exchangers, which facilitate the desired heat exchange, while keeping the investment and operating costs to a minimum value. Fuzzy approach is employed in the present work to select the optimum minimum 
approach temperature which accordingly leads to minimum total annual cost.

\section{FUZZY SET THEORY}

Zadeh [13] first formulated fuzzy set theory in 1965; the theoretical information are available in Dubois and Prade [14]. It will just explain the basic notions of such theory and the typical applications in chemical engineering. Fuzzy set theory is able to describe uncertainty that can arise in a lot of manners in chemical engineering. Following Kraslawski [15], distinguished two main kinds of uncertainty: ambiguity and imprecision. A proposition is ambiguity if its truth or its falsity cannot be definitely established. A proposition is imprecise if its value is not sufficiently determined with respect to a given scale. Both ambiguity and imprecision can be also divided into many uncertainty types. Here, the uncertainties of heuristic rules are on the latter type, because of the lack of precision of terms like "high" or "small".

A fuzzy set A in the space $X=\{x\}$ can be defined as the set:

$$
\begin{array}{cl}
\mathbf{A}= & \left\{x, \mu_{A}(X)\right\} \\
\mu_{A}: X \rightarrow[0,1] & \forall \mathrm{x} \in \mathrm{X} \\
X \rightarrow \mu_{\mathrm{A}}(X) &
\end{array}
$$

$\mu_{A}(X)$ : Expresses the grade of membership of $\mathrm{x}$ in A

$\mu_{A}(X)=0$ Means that $\mathrm{x}$ is indefinitely a member of $\mathrm{A}$

$\mu_{A}(X)=1$ Means that $\mathrm{x}$ is definitely a member of $\mathrm{A}$

The intermediate values of the membership function denote partial defined to some extent, membership of A.

The fuzzy set theory is, in effect, a step toward rapprochement between the precision of classical mathematics and the pervasive imprecision of the real world, a rapprochement born of the incessant human quest for a better understanding of mental process and cognition Zadeh [16].

Some algebraic operations can be defined on fuzzy set Dubois D. and Prade H. [14] like:

$$
\begin{array}{ll}
\text { Union } & \mu_{A \cup B}=\max \left(\mu_{\mathrm{A}}, \mu_{B}\right) \\
\text { Intersection } & \mu_{A \cap B}=\min \left(\mu_{\mathrm{A}}, \mu_{B}\right)
\end{array}
$$

A decision is to be made by evaluating all the related rules at different levels in a knowledge base. The evaluations are carried out according to the MAX-MIN algorithm.

$\mu_{j}(x)=\max \left\{\min _{k \in K}\left\{\mu_{j 1,}\left(x_{1}\right), \mu_{j 2},\left(x_{2}\right), \ldots . . \mu_{j k,}\left(x_{k}\right)\right\}\right\}$

Where:

$\mu_{j k},(x)=$ Membership function of variable $\mathrm{x}$ in fuzzy set $\mathrm{k}$ representing the $\mathrm{k}^{\text {th }}$ antecedent of the $\mathrm{i}^{\text {th }}$ rule at the $\mathrm{j}^{\text {th }}$ level.

The MIN operation yields a set truth values $\left(\tau_{I}\right)$ through evaluation of the membership functions of all the rules. Then, a single rule is selected by performing the MAX operation, i.e.

$$
\tau=\max \left\{\tau_{1}, \tau_{2}, \tau_{3}, \ldots \ldots, \tau_{I}\right\}
$$

This selected rule is activated or fired. The same operation is repeated at the succeeding level based on the information received from the preceding level.

\section{FUZZY APPROACH STRATEGY}

Based on the strategy of Fuzzy set theory the following algorithm was developed to select optimal heat exchanger networks and it consists of four steps:

Step1. For different values of minimum approach temperature, get the minimum heating $\left(\mathrm{Q}_{\mathrm{H}}\right)$ requirement \& the minimum cooling $\left(\mathrm{Q}_{\mathrm{C}}\right)$ requirement from the cascade diagram according to Linnhoff, B., and Hindmarsh [3], for each value of $\Delta \mathrm{T}$, normalized $\left[\left(\mathrm{Q}_{\mathrm{H}}\right)_{\min },\left(\mathrm{Q}_{\mathrm{C}}\right)_{\min }\right]$ can be derived by application of a linear programming code, two bounds $(\boldsymbol{f})_{\mathrm{min}}$ $\&(f)_{\max }$ can be computed, and the normalized variables can be estimated by:

$\mu=\frac{\left(f-f_{\text {max }}\right)}{\left(f_{\text {min }}-f_{\text {max }}\right)}$, Where

$\mu=0$ If $f=f_{\text {max }} ; \mu=1$ If $f=f_{\text {min }}$

Step2. Calculate the minimum value of parameters according to equation (4).

Step3. The final step corresponds to the choice of the best weight Index. The operation is carried out by comparing $(\tau)$ values for all minimum approach temperature and by choosing the greatest one according to equation 5 .

Step4. Fuzzy approach strategy

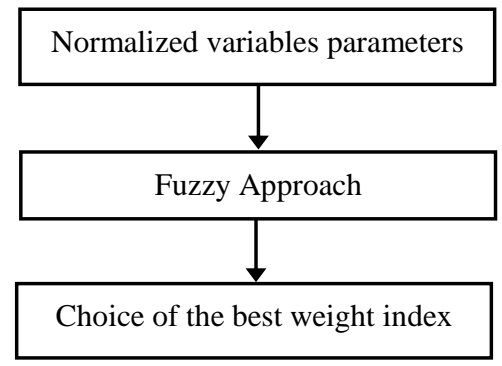

Fig.1. Fuzzy Approach Strategy

\section{EXAMPLES}

The proposed method will be tested using two case studies reported in the literature, for comparison.

\subsection{Example 1}

Our problem here is H4SP1R, two hot and two cold streams, one cold utility and one hot utility stream taken from Shenoy [17]. The specifications for all streams, plant data are shown in Table 1 and 2. The overall heat transfer coefficients for all matches are the same. The example was solved by Fuzzy approach method to minimize Total Annual Cost (TAC). The summary of results of the proposed method is shown in Table 
5 , which confirmed with results obtained, thus the optimum $\Delta \mathrm{T}=25^{\circ} \mathrm{C}$ which give a global cost of $(\$ / \mathrm{Yr} 287,875)$ and a weight index of (0.553), which ensures our strategy. The final optimum network is shown in Fig 4. The area requirement is $1886.8 \mathrm{~m}^{2}$ and the total capital cost is $(\$ / \mathrm{Yr} 287,875)$. The solution obtained by the proposed method is lower than the solution produced by MINLP and Supertarget method as shown in Table 5.

\subsection{Example 2}

This problem involves finding a cost-optimal network of exchangers for six hot streams and four cold streams one cold utility and one hot utility stream having the same heat transfer coefficients. This case was studied first by Ahmed [18]. The input data for the problem is given in Table 6 and 7 The summary of results of the proposed method is shown in Table 8 , which confirmed with results obtained, thus the optimum $\Delta \mathrm{T}=17.5^{\circ} \mathrm{C}$ with $\mathrm{TAC}(\$ / \mathrm{Yr} 2,647,630)$ and a weight index of (0.500), which ensures our strategy. The final optimum network is shown in Fig 7. The annual cost of hot utility and cold utility is $(\$ / \mathrm{Yr} 2,104,705)$. The area requirement is $55,513 \mathrm{~m}^{2}$ and the total capital cost is (\$/Yr 3,330,832).

Table 1: Stream and cost data for Example 1

\begin{tabular}{cccc}
\hline Stream & $\mathbf{T}_{\text {in }}\left({ }^{\circ} \mathbf{C}\right)$ & $\mathbf{T}_{\text {out }}\left({ }^{\circ} \mathbf{C}\right)$ & $\begin{array}{c}\mathbf{M C p} \\
\mathbf{k W} /{ }^{\circ} \mathbf{C}\end{array}$ \\
\hline $\mathbf{H 1}$ & 175 & 45 & 10 \\
$\mathbf{H 2}$ & 125 & 65 & 40 \\
$\mathbf{C 3}$ & 20 & 155 & 20 \\
$\mathbf{C 4}$ & 40 & 112 & 15 \\
\hline $\mathbf{H U}$ & 180 & 179 & - \\
\hline $\mathbf{C U}$ & 15 & 25 & - \\
\hline
\end{tabular}

Table 2: Plant Data for Example 1

\begin{tabular}{cll}
\hline $\begin{array}{c}\text { Utility } \\
\text { data }\end{array}$ & Fuel gas cost & $120(\$ / \mathrm{kW} . \mathrm{yr})$ \\
\hline Plant & Rate of interest $(\mathrm{i})$ & $10(\$ / \mathrm{kW} . \mathrm{yr})$ \\
Data & Lifetime $(\mathrm{n})$ & 5 years \\
\hline Capital & $A_{f}:$ Annualization factor & $(1+i)^{n} / n$ \\
cost data & Installed unit cost $(\$)$ & $30000+750(\mathrm{~A})^{0.81}$ \\
& U (overall heat transfer & $0.2\left(\mathrm{~kW} / \mathrm{m}^{2 \circ} \mathrm{C}\right)$ \\
& coefficients) & \\
\hline
\end{tabular}

Table 3: Results of Fuzzy Approach for Example 1

\begin{tabular}{cccccc}
\hline $\begin{array}{c}\Delta \mathbf{T} \\
\left({ }^{\circ} \mathbf{C}\right)\end{array}$ & $\boldsymbol{\mu}_{\mathbf{1}}$ & $\boldsymbol{\mu}_{\mathbf{2}}$ & $\boldsymbol{\mu}_{\mathbf{3}}$ & $\min$ & $\boldsymbol{\tau}$ \\
\hline $\mathbf{1 5}$ & 0.375 & 0.926 & 0.926 & 0.375 & \\
$\mathbf{2 0}$ & 0.500 & 0.741 & 0.739 & 0.500 & \\
$\mathbf{2 5}$ & 0.625 & 0.556 & 0.553 & 0.553 & $\mathbf{0 . 5 5 3}$ \\
$\mathbf{3 0}$ & 0.750 & 0.370 & 0.367 & 0.367 & \\
$\mathbf{3 5}$ & 0.875 & 0.185 & 0.181 & 0.181 & \\
\hline
\end{tabular}

Table 4: Cost Analysis of HEN at different $\Delta T_{\min }$ for Example 1

\begin{tabular}{ccccc}
\hline$\Delta \mathbf{T}_{\text {min }}$ & $\begin{array}{c}\mathbf{Q}_{\mathbf{H}} \\
(\mathbf{k W})\end{array}$ & $\begin{array}{c}\mathbf{Q}_{\mathbf{C}} \\
(\mathbf{k W})\end{array}$ & $\begin{array}{c}\text { Area } \\
\left(\mathbf{m}^{\mathbf{2}}\right)\end{array}$ & $\begin{array}{c}\text { Annualized } \\
\text { total cost } \\
\mathbf{( \$ / Y r})\end{array}$ \\
\hline $\mathbf{1 5}$ & 430.0 & 350.0 & 3105 & 309,065 \\
\hline $\mathbf{2 0}$ & 605.0 & 525.0 & 2360 & 292,357 \\
\hline $\mathbf{2 5}$ & 780.0 & 700.0 & 1886 & $\mathbf{2 8 7 , 8 7 5}$ \\
\hline $\mathbf{3 0}$ & 955.0 & 875.0 & 1555 & 290,250 \\
\hline
\end{tabular}

\begin{tabular}{ccccc}
\hline$\Delta \mathbf{T}_{\min }$ & $\mathbf{Q}_{\mathbf{H}}$ & $\mathbf{Q}_{\mathbf{C}}$ & Area & Annualized \\
\hline $\mathbf{3 5}$ & 1130 & 1050 & 1307 & 296,833 \\
\hline
\end{tabular}

Table 5: Comparison of results for Example 1

\begin{tabular}{cccc}
\hline & $\begin{array}{c}\text { Shenoy } \\
{[\mathbf{1 7 ]}}\end{array}$ & $\begin{array}{c}\text { Hojjati } \\
{[\mathbf{1 9 ]}}\end{array}$ & $\begin{array}{c}\text { Present } \\
\text { Work }\end{array}$ \\
\hline Method & Supertarget & MINLP & F.A \\
$\Delta \mathbf{T}\left({ }^{\circ} \mathbf{C}\right)$ & - & - & 25 \\
Hot Utility $(\mathbf{k W})$ & 400 & 400 & 780 \\
Cold Utility $(\mathbf{k W})$ & 320 & 320 & 700 \\
Total area $\left(\mathbf{m}^{\mathbf{2}}\right)$ & 2041 & 1590 & 1886.8 \\
\hline Global Cost $\mathbf{( \$ \mathbf { y r } )}$ & 383,475 & 325,502 & 287,875 \\
\hline
\end{tabular}

Table 6: Stream and cost data for Example 2

\begin{tabular}{cccc}
\hline \multicolumn{4}{c}{ Table 6: Stream and cost data for Example 2 } \\
\hline H1 & $\mathbf{T}_{\text {in }}\left({ }^{\circ} \mathbf{C}\right)$ & $\mathbf{T}_{\text {out }}\left({ }^{\circ} \mathbf{C}\right)$ & $\begin{array}{c}\mathbf{M ~ C p} \\
\left(\mathbf{k W} /{ }^{\circ} \mathbf{K}\right)\end{array}$ \\
\hline H2 & 85 & 45 & 156.3 \\
H3 & 120 & 40 & 50 \\
H4 & 125 & 35 & 23.9 \\
H5 & 56 & 46 & 1250 \\
H6 & 90 & 86 & 1500 \\
C1 & 225 & 75 & 50 \\
C2 & 40 & 55 & 466.7 \\
C3 & 55 & 65 & 600 \\
C4 & 65 & 165 & 180 \\
\hline HU & 10 & 170 & 81.3 \\
\hline CU & 200 & 198 & - \\
\hline
\end{tabular}

Table 7: Plant Data Example 2

\begin{tabular}{cll}
\hline $\begin{array}{c}\text { Utility } \\
\text { data }\end{array}$ & $\begin{array}{l}\text { Fuel gas cost } \\
\text { Cooling water cost }\end{array}$ & $\begin{array}{c}100(\$ / \mathrm{kW} . \mathrm{yr}) \\
15(\$ / \mathrm{kW} . \mathrm{yr})\end{array}$ \\
\hline $\begin{array}{c}\text { Plant } \\
\text { Data }\end{array}$ & $\begin{array}{l}\text { Rate of interest (i) } \\
\text { Lifetime (n) }\end{array}$ & $\begin{array}{c}10 \% \\
10 \text { years }\end{array}$ \\
\hline & $A_{f}:$ Annualization factor & $i(1+i)^{n}$ \\
Capital & Installed unit cost $(\$)$ & $(1+i)^{n}-1$ \\
cost data & U (overall heat transfer & $60(\mathrm{~A})$ \\
& coefficients) & $0.025\left(\mathrm{~kW} / \mathrm{m}^{2} \mathrm{~K}\right)$ \\
\hline
\end{tabular}

Table 8: Results of Fuzzy Approach Example 2

\begin{tabular}{cccccc}
\hline $\boldsymbol{\Delta T}$ & $\boldsymbol{\mu}_{\mathbf{1}}$ & $\boldsymbol{\mu}_{\mathbf{2}}$ & $\boldsymbol{\mu}_{\mathbf{3}}$ & $\boldsymbol{m i n}$ & $\boldsymbol{\tau}$ \\
\hline $\mathbf{1 0}$ & 0.286 & 1.000 & 1.000 & 0.286 & \\
$\mathbf{1 2 . 5}$ & 0.357 & 0.845 & 0.845 & 0.357 & \\
$\mathbf{1 5}$ & 0.429 & 0.691 & 0.691 & 0.429 & \\
$\mathbf{1 7 . 5}$ & 0.500 & 0.590 & 0.590 & $\mathbf{0 . 5 0 0}$ & $\mathbf{0 . 5 0 0}$ \\
$\mathbf{2 0}$ & 0.571 & 0.425 & 0.425 & 0.425 & \\
$\mathbf{2 5}$ & 0.714 & 0.395 & 0.395 & 0.395 & \\
$\mathbf{3 0}$ & 0.857 & 0.265 & 0.265 & 0.265 & \\
\hline
\end{tabular}



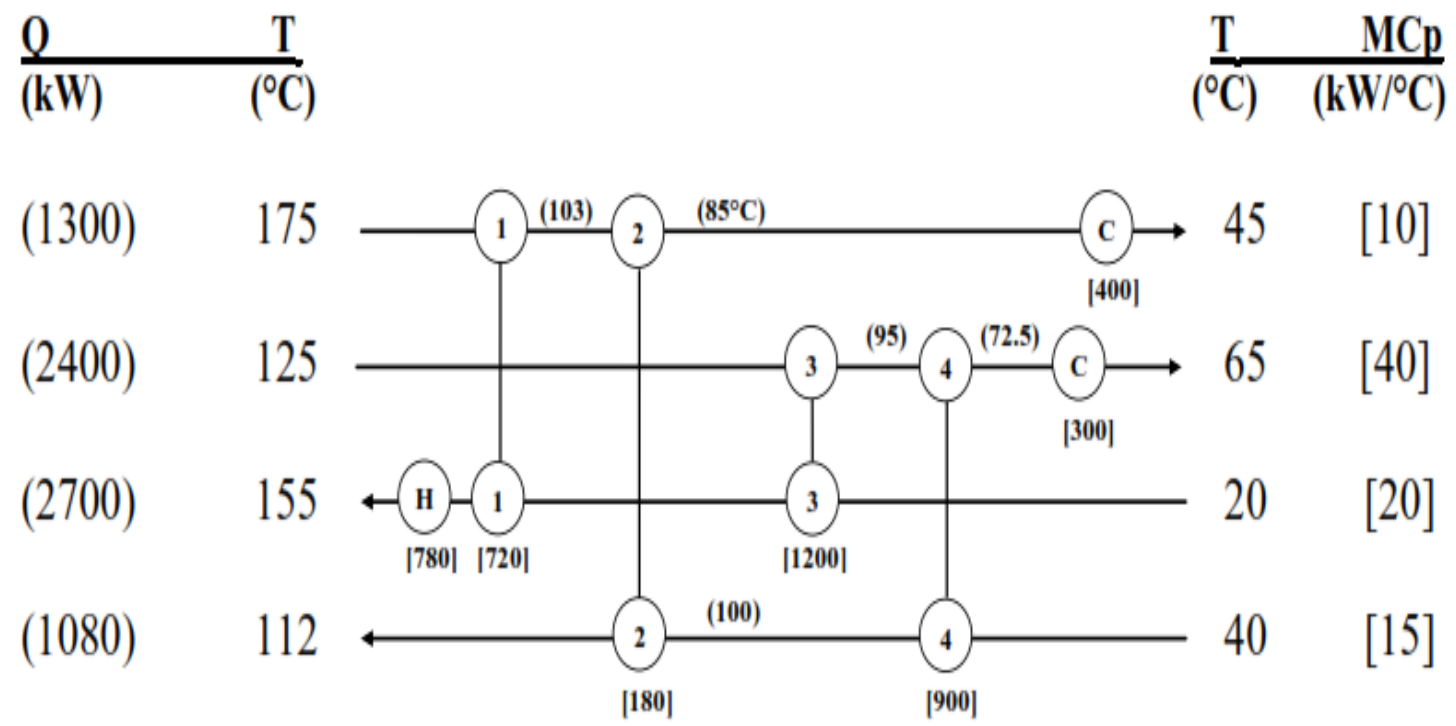

Fig.2. Optimum design for HEN synthesis problem H4SP1R at $\Delta \mathrm{Tmin}=25^{\circ} \mathrm{C}$

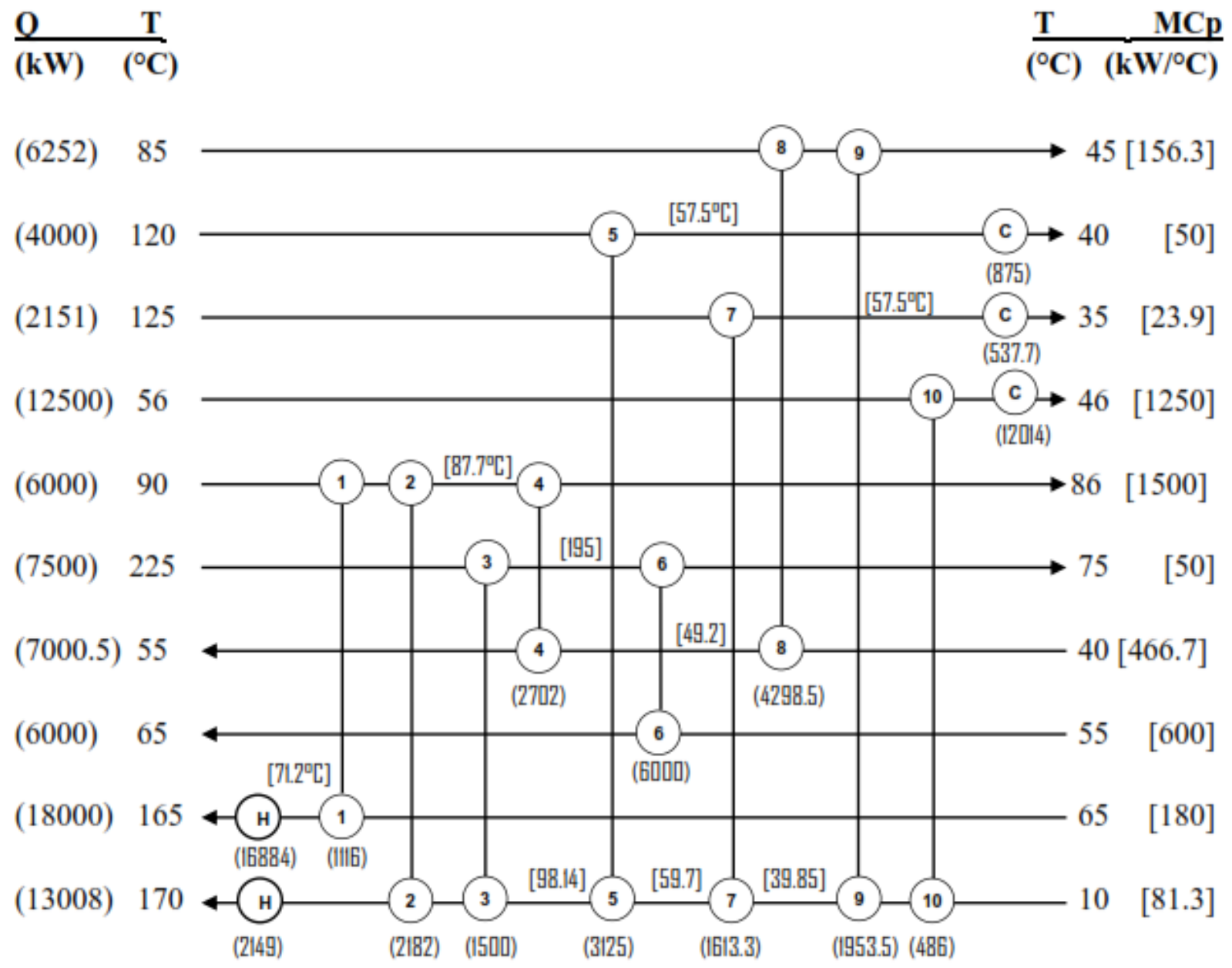

Fig.3. Grid diagram for HEN synthesis problem 10SP1 at $\Delta \operatorname{Tmin}=17.5^{\circ} \mathrm{C}$ 
Table 9: Cost Analysis of HEN at different $\Delta T_{\min }$ for Example 2

\begin{tabular}{ccccc}
\hline$\Delta \mathbf{T}_{\mathbf{m i n}}$ & $\begin{array}{c}\mathbf{Q}_{\text {Hmin }} \\
(\mathbf{k W})\end{array}$ & $\begin{array}{c}\mathbf{Q}_{\mathbf{C m i n}} \\
(\mathbf{k W})\end{array}$ & $\begin{array}{c}\text { Area } \\
\left(\mathbf{m}^{2}\right)\end{array}$ & $\begin{array}{c}\text { Annualized } \\
\text { total cost } \\
(\mathbf{\$} / \mathbf{Y r})\end{array}$ \\
\hline $\mathbf{1 0}$ & 15399 & 9795 & 122,634 & $2,886,189$ \\
\hline $\mathbf{1 2 . 5}$ & 16770 & 11166 & 88,711 & $2,712,060$ \\
\hline $\mathbf{1 5}$ & 18139 & 12534 & 72,979 & $2,715,645$ \\
\hline $\mathbf{1 7 . 5}$ & 19033 & 13429 & 55,513 & $\mathbf{2 , 6 4 7 , 6 6 0}$ \\
\hline $\mathbf{2 0}$ & 19608 & 14004 & 55,070 & $2,709,499$ \\
\hline $\mathbf{2 5}$ & 20760 & 15156 & 47,936 & $2,772,104$ \\
\hline $\mathbf{3 0}$ & 21911 & 16307 & 29,669 & $2,725,819$ \\
\hline
\end{tabular}

Table 10: Comparison of results of HEN Example 2

\begin{tabular}{|c|c|c|c|c|}
\hline & $\begin{array}{c}\text { Ahmed } \\
{[18]}\end{array}$ & $\begin{array}{c}\text { Ravagnani } \\
{[20]}\end{array}$ & $\begin{array}{c}\text { Krishna } \\
{[21]}\end{array}$ & $\begin{array}{l}\text { This } \\
\text { Work }\end{array}$ \\
\hline Method & $\begin{array}{l}\text { Super- } \\
\text { target }\end{array}$ & $\begin{array}{c}\text { Pinch + } \\
\text { (GA) }\end{array}$ & (DEM) & F.A. \\
\hline$\Delta \mathrm{T}\left({ }^{\circ} \mathrm{C}\right)$ & 10 & 24 & 19.46 & 17.5 \\
\hline $\begin{array}{l}\text { Hot Utility } \\
(\mathbf{k W})\end{array}$ & 15,400 & 20,529 & 20,745 & 19,033 \\
\hline $\begin{array}{l}\text { Cold Utility } \\
\quad(\mathbf{k W})\end{array}$ & 9,796 & 14,923 & 15,139 & 13,427 \\
\hline $\begin{array}{c}\text { Total area } \\
\left(\mathbf{m}^{2}\right)\end{array}$ & - & 56,000 & 56,085 & 55,513 \\
\hline $\begin{array}{c}\text { Global Cost } \\
(\mathrm{M} \$ \mathbf{y r})\end{array}$ & 7.074 & 5.672 & 5.666 & 5.435 \\
\hline
\end{tabular}

\section{CONCLUSIONS}

The present study explores new systematic method for synthesis heat exchanger network. The proposed method when applied to problems previously reported in the literature yielded optimum solutions which are consistent with different approach. It is evident that the performance of the Fuzzy approach is quite encouraging, characterized by its simplicity and can be implemented by hand calculations.

The results of case studies show that the present strategy is both robust and accurate in finding out global optimum cost \& optimum minimum approach temperature in comparison with previous works, which ensures its economic effectiveness

\section{Nomenclature}

$\begin{array}{ll}\text { LP } & \text { Linear Programming } \\ \text { NLP } & \text { Non Linear Programming } \\ \text { MILP } & \text { Mixed Integer Linear Programming } \\ \text { MINLP } & \text { Mixed Integer Non Linear Programming } \\ \text { Max } & \text { Maximum } \\ \text { Min } & \text { Minimum } \\ f_{\text {min }} & \text { Minimum bound of linear programming } \\ f_{\max } & \text { Maximum bound of linear programming } \\ \Delta T_{\min } & \text { Minimum approach temperature } \\ \mathrm{T}_{\text {in }} & \text { Inlet Temperature }\left({ }^{\circ} \mathrm{C}\right) \\ \mathrm{T}_{\text {out }} & \text { Outlet Temperature }\left({ }^{\circ} \mathrm{C}\right) \\ \text { MCp } & \text { Heat capacity flowrate } \\ \text { HU } & \text { Hot Utility } \\ \text { CU } & \text { Cold Utility } \\ \text { FA } & \text { Fuzzy Approach } \\ \text { W.I } & \text { Weight Index } \\ \text { TAC } & \text { Total Annualized Cost }\end{array}$

GA

DEM

$\mu_{1}$

$\mu_{2}$

$\mu_{3}$

Genetic Algorithm

Differential Evolution Method

Normalized $\Delta \mathrm{T}$

Normalized $\mathrm{Q}_{\mathrm{H}}$

Normalized $\mathrm{Q}_{\mathrm{C}}$

\section{REFERENCES}

[1] Masso A. H. and Rudd D. F., "The Synthesis of System Designs - II: Heuristic Structuring", AIChE Journal, Vol. 15, No. (1): pp. 10-17, (January 1969).

[2] Furman K. C. and Sahinidis N. V., "A Critical Review and Annotated Bibliography for Heat Exchanger Network Synthesis in the 20th Century", Ind. Eng. Chem. Res., Vol. 41, No. (10): pp. 2335-2370, (2002).

[3] Linnhoff B. and Hindmarsh E., "The Pinch Design Method for Heat Exchanger Networks". Chem. Eng. Sci., Vol. 38: pp. 745-763, (1983). An important step in development of PA.

[4] Linnhoff B. and Flower J. R., "Synthesis of Heat Exchanger Networks: Part 1: Systematic Generation of Energy Optimal Networks", AIChE Journal, Vol. 24: pp.633 (1978a).

[5] Linnhoff B. and Flower J. R., "Synthesis of Heat Exchanger Networks: Part 2: Evolutionary Generation of Networks with various Criteria for Optimality", AIChE Journal, Vol. 24: pp. 642 (1978b).

[6] Linnhoff B. and Ahmad S., "Cost Optimum Heat Exchanger Networks - 1. Minimum Energy and Capital Using Simple Models for Capital Cost", Comp. Chem. Eng., Vol. 14: pp. 729, (1990).

[7] Papoulias S. A. and Grossmann I. E., "A Structural Optimization Approach in Process Synthesis - II. Heat Recovery Networks", Comp. Chem. Eng., Vol. 7, No. (6): pp. 707-721, (1983). An important for MP supported HEN synthesis - part 1 .

[8] Papoulias S. A. and Grossmann I. E., "A structural optimization approach in process synthesis - III. Total processing systems". Comp. Chem. Eng., Vol. 7: pp. 723-734, (1983). An important for MP supported HEN synthesis - part 2.

[9] Yee T. F., Grossmann I. E. and. Kravanja Z., "Simultaneous Optimization Models for Heat Integration - I. Area and Energy Targeting and Modeling of MultiStream Exchangers. Comp. Chem. Eng., Vol. 14, No. (10): pp. 1151-1164, (1990a).

[10] Yee T. F. and Grossmann I. E., "Simultaneous Optimization Models for Heat Integration - II. Heat Exchanger Network Synthesis", Comp. Chem. Eng., Vol. 14, No. (10): pp. 1165-1184, (1990b).

[11] Ravagnani, M. A. S. S., Silva, A. P., and Andrade, A. L. "Detailed equipment design in heat exchanger networks synthesis and optimization". Applied Thermal Analysis, Issue 23, (141-151), 2003

[12] Hussein, M.H., Moselhy, H., Aly S., Awad, M. E. "Fuzzy Analogical Gates Approach for Heat Exchangers Networks". International Journal of Computer Applications. Vol. 73, No. (21): pp.1-8, (July 2013) 
[13] Zadeh L.A., Fuzzy sets, Inform. Control. Vol. 8 (1965), pp. 338.

[14] Dubois D. and H. Prade (1980), Fuzzy sets and systems, Academic press, New York.

[15] Kraslawski A., Review of applications of various types uncertainty in chemical Proc., Vol. 26 (1989) 185. engineering. Chem. Eng.

[16] Zadeh L.A., Introduction to the theory of fuzzy subsets, Academic press, Vol. 1, (1975), pp. ix-x.

[17] Shenoy U. V., "Heat Exchanger Network Synthesis Process Optimization by Energy and Resource Analysis", Gulf Publishing Company Houston, Texas, (1995).

[18] Ahmad S., "Heat Exchanger Networks: Cost Tradeoffs in
Energy and Capital ". Ph.D. Thesis. UK: UMIST Manchester. (1985).

[19] Hojjati M. R. and Omidkhah M. R., "Cost Effective Heat Exchanger Network Design with Mixed Materials of Construction", Iran. Journal Chem. \& Chem. Eng. Journal. Vol. 23, No. (2), (2004).

[20] Ravagnani M. A. S. S., Silva A. P., Arroyo P. A., and Constantino A. A., "Heat Exchanger Network Synthesis and Optimization using Genetic Algorithm". App. Therm. Eng., Vol. 25: pp. 1003-1017, (2005).

[21] Krishna M. Yerramsetty C. V. and Murty S., "Synthesis of Cost-Optimal Heat Exchanger Networks using Differential Evolution", Comp. Chem. Eng., Vol. 32: pp. 1861-1876, (2008). 